\title{
Consolidation centers in city logistics: A cooperative approach based on the location routing problem
}

\author{
Sachin Nataraj ${ }^{a}$, Daniele Ferone ${ }^{\mathrm{b}}$, Carlos Quintero-Araujo ${ }^{c^{*}}$, Angel A. Juan ${ }^{\mathrm{d}}$ and Paola Festa $^{\mathrm{e}}$
}

${ }^{a}$ Sachin Nataraj: IN3 - Computer Science Dept., Universitat Oberta de Catalunya, Barcelona, Spain

${ }^{b}$ Daniele Ferone: Dept. of Informatics, Systems and Communication, University of Milano-Bicocca, Milano, Italy

${ }^{c}$ Carlos Quintero-Araújo: International School of Economics and Administrative Sciences, Universidad de La Sabana, Chía, Colombia

${ }^{d}$ Angel A. Juan: IN3 - Computer Science Dept., Universitat Oberta de Catalunya, Barcelona, Spain

ePaola Festa: Dept. of Mathematics and Applications, University of Napoli Federico II, Napoli, Italy

C H R O N I C L E

\section{Article history:}

Received December 132018

Received in Revised Format

January 62019

Accepted January 92019

Available online

January 92019

Keywords:

Location Routing Problem

Vehicle Routing Problem

Metaheuristics

Urban Consolidation Center

Biased Randomization

Horizontal Cooperation

\section{A B S T R A C T}

In the context of city logistics, freight transportation is one of the prominent causes of traffic congestion, high levels of pollution, and safety concerns. To decrease the negative impact of these issues, different methods have been traditionally implemented. On the one hand, the location of urban consolidation Centers (UCCs) near a city can be used to consolidate freight delivery services. Therefore, the number of trucks moving in urban areas can be reduced. On the other hand, Horizontal Cooperation can also help to reduce environmental impact while increasing service level. This paper combines both strategies, that is, we deal with the location of UCCs and, simultaneously, we analyze different scenarios where the players of different supply chain processes exhibit various levels of cooperation. Thus, different levels of cooperations regarding routing and UCCs-location decisions are considered in the following scenarios: (a) non-cooperative case, in which all decisions are decentralized (i.e., each enterprise solves its own vehicle routing problem); (b) low-cooperative case, where depot capacities are shared but the customers are still being served by each company's fleet of vehicles; (c) semicooperative case, based on centralized route planning decisions (i.e. facilities and fleets are shared among participating enterprises); and (d) fully cooperative scenario, where the routing plans and facility-location decisions are taken by consensus amongst all the participants. In order to estimate the benefits of both strategies, we propose a flexible metaheuristic algorithm to deal with the combined location and routing problem under the different cooperative scenarios. Our results show impressive benefits of the proposed approach.

\section{Introduction}

Urban goods distribution is a crucial component for the well-being of an inner city. However, the transportation of goods generates noise, air pollution, congestion and lower levels of traffic safety, which are troublesome issues in urban logistics. In addition, some urban structural designs and policies that have been implemented to reduce these issues might have a negative impact on the efficiency of transportation activities. This results in higher travel times, reduced service quality (reliability), and logistic systems using more vehicles than required (Van Binsbergen \& Visser, 1999).

* Corresponding author

E-mail: carlosqa@unisabana.edu.co (C. Quintero-Araujo)

2019 Growing Science Ltd.

doi: $10.5267 /$ j.ijiec.2019.1.001 
Thus, Horizontal Cooperation (HC) appears as an alternative to execute transportation tasks (SerranoHernandez et al., 2017). HC has the potential to reduce logistics costs as well as the related environmental impact of delivery tasks, especially those associated with greenhouse gas emissions and noise. The sharing of information (e.g. customer demands or geo-positional data of available vehicles) and facility capacities among members of the same supply chain level promises to be an innovative transportation concept in last-mile deliveries. HC in logistics involves two or more companies cooperating to achieve a common goal, which is usually related to the optimization of the global distribution cost. Through close cooperation the partnering agents aim at reaching higher productivity levels by optimizing the usage of vehicle capacity, reducing the number of empty trips, improving the allocation of vehicles and depots, and lowering costs of complementary tasks in order to increase the efficiency of their logistics network (Cruijssen et al., 2007a). Different degrees of cooperation can be considered, as pointed out by QuinteroAraujo et al. (2019).

Urban consolidation centers (UCCs) are locations in or near cities where freight vehicles (long haul) deliver goods. These goods are then consolidated and delivered to numerous points across the city, ideally using eco-friendly vehicles (electric or hybrid vehicles). Using UCCs considerably cuts down the number of kilometers traveled by larger and more polluting freight vehicles, which saves fuel and reduces emissions. Hence, making cities cleaner and healthier for their citizens.

According to the advantages pointed out by Thompson and Taniguchi (2008), the creation of UCCs allows for a much more efficient urban logistics system, with the same capacity of service than conventional systems but with lower environmental impacts. Optimally determining the location and operation of UCCs would not only have an economic impact, but also an environmental and a social one as well. The Location Routing Problem (LRP) is incorporated in the UCC problem. The LRP is one of the most complete problems in logistics and transportation, since it involves all the decision levels involved in the design and management of supply chains, these are: (i) strategic decision making for the location of UCCs; (ii) tactical decision making regarding the customer allocation to available UCCs; and (iii) operational decision making to assign delivery routes to each UCC and its associated customers.

Traditionally, these different decision-making levels have been considered independently in the literature. Thus, in order to fulfill this gap, we propose the combined use of these strategies. In addition, for the first time in the literature, we assume that some of the companies involved in the final distribution of goods to customers are not willing to participate in the $\mathrm{HC}$ alliance. As mentioned before, this paper concentrates on the implementation of HC strategies when considering the location of consolidation centers and the associated vehicle routing to reduce operational costs and environmental impacts. In order to achieve this goal, an integrated approach based on the LRP is adopted to find the location of urban consolidation centers. The LRP is a combination of the Facility Location Problem (FLP) and the Vehicle Routing Problem (VRP), so it is an NP-hard problem. In addition, these scenarios are observed and analyzed according to different percentages of cooperation among several distribution companies. This work differs from previous ones by considering that there are companies which could not be interested in being part of the cooperation agreement. In that sense, we have considered for each cooperative scenario (i.e. scenarios 2, 3, and 4, explained later) three sub-scenarios with $50 \%, 75 \%$, and $100 \%$ of companies participating in the partnership, respectively.

According to the level of cooperation, the aforementioned scenarios are addressed, and the resulting optimization problems are solved by employing a metaheuristic algorithm. This algorithm enables us to deal with the combined location and routing problems. The structure of the paper is as follows. Section 2 presents a literature review on HC concepts, UCCs, and the LRP. Section 3 introduces the problem under study. Section 4 describes the methodology used in this work, together with the proposed solution approach. In Sections 5 and 6 we specify the experiments that were carried out and present the results of the executed tests, respectively. Finally, Section 7 presents some conclusions and outlines further research lines. 


\section{Literature Review}

The literature review is structured in three parts. The first part reviews the benefits and the types of HC of land-side transportation and logistics in urban areas. The second part concentrates on the implementation of HC, especially on the advantages of employing UCCs, and the impact of UCCs in city logistics. Finally, the third part focuses on the LRP for allocation of UCCs to optimize transportation in city logistics.

\subsection{Horizontal Cooperation}

When it comes to city logistics development, $\mathrm{HC}$ is widely discussed as one of the innovative solutions, which comprises the cooperation of participants in different supply chain levels in urban areas (Cruijssen et al., 2007a). Despite the practice of HC is well documented for maritime and aviation transportation, it is still an emerging topic in the context of land-side transportation and logistics (Pomponi et al., 2013). Synergies obtained from cooperation are consequently the main reasons for implementing HC practices. Cruijssen et al. (2007b) explained in detail the role of $\mathrm{HC}$ in transportation and logistics and its implications. Vanovermeire et al. (2014) proposed a strategy to allocate costs among the partners.

Perez-Bernabeu et al. (2015) analyzed HC in road transportation under different scenarios, where distance and environmental costs were considered. To understand the importance of HC in city logistics, it is also important to consider non-cooperative scenarios. In this regard, Quintero-Araujo et al. (2017b) compared non-cooperative and $\mathrm{HC}$ by formulating a multi-depot vehicle routing problem and embedding Monte Carlo simulation into a metaheuristic process. Quintero-Araujo et al. (2016) analyzed the effects of implementing $\mathrm{HC}$ among three Colombian companies, while considering uncertain demands. Later, Quintero-Araujo et al. (2017c) extended the previous scenarios by integrating facility location decisions to the routing process. Recently, Muñoz-Villamizar et al. (2018) analyzed the use of electric vehicles in collaborative urban freight distribution. Regarding collaborative strategies in vehicle routing, readers are referred to Gansterer and Hartl (2018) who present an updated review on the topic.

$\mathrm{HC}$ is often discussed in the context of city logistics development, which is based on the cooperation of different supply chain actors in urban areas. Serrano-Hernandez et al. (2017) analyzed the main benefits and optimization challenges associated with the use of HC at the strategic, tactical, and operational levels.

\subsection{Urban Consolidation Centers}

UCCs play an important role in supply chain management, as they constitute the main facilities where the consolidated cargo is transshipped from large and polluting vehicles to smaller environmentally friendly ones. These smaller vehicles are utilized to perform the last-mile distribution in urban zones. This configuration aims to protect urban and restricted areas from high traffic density and environmental externalities, thus improving safety and quality of life. Although costly and time demanding, it has been proved that these city logistics strategies are effective, relieve traffic, and safeguard the environment (Grimm et al., 2008). Allen et al. (2012) compared 114 UCC schemes in 17 countries. These schemes have been either feasibly studied, made a trial run or fully operated in the past 40 years. Some of the best known implementations of consolidation centers are in the Europeans cities of Nijmegen (Van Rooijen and Quak, 2010) and London (Browne et al., 2012; Patier \& Browne, 2010). Browne et al. (2011) evaluated the trial run made by a major office supplies company in central London to reduce freight traffic and its impacts by considering UCCs. This led to reductions in total distance and $\mathrm{CO}_{2}$ emissions of $20 \%$ and 54\%, respectively, per parcel delivered. De Assis Correia et al. (2012) presented a methodology to analyze the economic and environmental impacts of UCCs in Belo Horizonte (Brazil). To allocate the freight carriers, the main criteria is the selection of most appropriate locations for establishment of each facility and the solution of the corresponding vehicle routing for efficient delivery of goods to customers. Gogas and Nathanail (2017) provided a methodology for solving an FLP and an 
integrated assessment model used to evaluate the operation of UCCs. To achieve optimal transport in city logistics and to reduce environmental impacts, the location of the UCCs and the associated vehicle route planning for deliveries in urban areas are crucial. These two problems are solved as an integrated LRP.

\subsection{The Location Routing Problem}

The LRP comprises all decision levels (strategic, tactical, and operational) in supply chain management. Strategic decisions are related to the number and size of facilities to be opened, while tactical and operational ones are associated with customers' allocation to opened facilities and the corresponding distribution routes, respectively. In terms of classical optimization problems, the LRP combines the FLP -which is associated with strategic decisions-, and the multi-depot vehicle routing problem (MDVRP), which is related to customers' allocation to facilities and the subsequent route planning (Nagy \& Salhi, 2007). The benefits derived from considering routing decisions while locating facilities were firstly estimated in Salhi and Rand (1989). The authors proved that solving the associated subproblems (i.e., FLP and VRP) independently, does not necessarily generate optimal solutions. Despite the importance of the LRP in supply chain management, the number of published works is lower than the number of articles related to other VRP variants. However, the amount of publications related to the topic has increased considerably in recent years.

Muñoz-Villamizar et al. (2013) solved the combined LRP in urban scenario by using a hybrid algorithm which employs biased-randomization into several stages of the optimization process. This research was carried out considering real-life data. Prins et al. (2006) proposed a Greedy Randomized Adaptive Search Procedure (GRASP) based on an extended and randomized version of the Clarke and Wright (1964) savings (CWS) algorithm called RECWA. This is combined with a learning process to identify promising subsets of depots and Path Re-linking as a post optimization step. Quintero-Araujo et al. (2017a) presented an efficient and simple approach for solving the CLRP. The proposed method combines biased randomization techniques with perturbations of the allocation maps to generate good solutions for the CLRP.

Solving the VRP using green logistics comprises a number of problems. Reyes-Rubiano et al. (2018) proposed a metaheuristic approach for the MDVRP, while considering economic, environmental, and social dimensions. This paper also discusses how the cost values change according to the prioritized dimension. Further, Juan et al. (2014) discussed the VRP with multiple driving ranges by considering heterogeneous fleet and attempted to solve the problem by applying a multi-round heuristic algorithm.

\section{Description of Horizontal Cooperation Scenarios}

Four different scenarios of urban distribution are considered in this paper to study the effect of horizontal cooperation, in the context of a problem that combines the location of UCCs and the associated VRPs to serve customers demands in the most efficient way. In the following sub-sections, an overview of each scenario is provided.

\subsection{Non-Cooperative Scenario without UCCs}

In a non-cooperative scenario, we assume that each company serves its allocated customers from its central depot employing its own vehicles. Both the depot and the available vehicles have limited capacities. In other words, both the location of UCCs and the implementation of HC strategies are not considered. 


\subsection{Depot Cooperation without UCCs}

In this scenario, the location of UCCs is not considered, that is, each company uses its own central depot. While the objective function is to minimize the total cost, the main criterion is to implement HC in terms of sharing depots among companies. The problem constraints include that customers are served only by the company they were allocated to and are served only by this company's vehicles. That is, vehicles of different companies deliver the demand of their own customers, but the vehicles can depart from different depots, even if these are not the company's depot. Here, we study the following different percentages of $\mathrm{HC}$ among the companies and its impact on total cost and travel costs (including distances, times, and $\mathrm{CO}_{2}$ emissions):

a) $50 \%$ cooperation level: from the case study, only $50 \%$ of the companies share their depots (still, fleets are not shared, so each company delivers its own customers).

b) $75 \%$ cooperation level: $75 \%$ of the companies share their depot capacities (this includes the ones in the previous case plus a new $25 \%$ ).

c) $100 \%$ cooperation level: all companies share their depot capacity with others (still, each company services its own customers).

\subsection{Depot and Fleet Cooperation without using UCCs}

Once again, the location of UCCs is not taken into account in this scenario. In addition, companies cooperate to execute the goal of serving different customers. Here we assume the cooperation includes sharing of depot capacities as well as the fleet of vehicles. Each customer must be assigned to an existing depot and, subsequently, a set of routes is planned to satisfy all customer demands. This scenario corresponds to a MDVRP. As before, different percentage levels of cooperation, in terms of participating companies, are considered: $50 \%, 75 \%$, and $100 \%$.

\subsection{Depot and Fleet Cooperation using UCCs}

In this fully-cooperative scenario with UCCs the degree of joint supply chain decisions increases. By sharing customer information, storage facilities, and vehicle capacities, route planning can be optimized on a supply chain level through a more efficient customer-depot allocation. Apart from jointly planning the delivery routes, this scenario also includes the joint determination of the most efficient number and location of logistics facilities. As before, this scenario is analyzed with $50 \%, 75 \%$, and $100 \%$ of cooperating enterprises. This scenario corresponds to a LRP, which integrates: (i) facility location decisions; (ii) customer assignment; and (iii) delivery route planning (Prodhon \& Prins, 2014).

\section{Solving Methodology}

Once all scenarios have been defined, our methodology consists of: (i) identifying the related optimization problems; (ii) developing a general algorithm to efficiently solve all scenarios; and (iii) analyzing the obtained results. Scenario 1 can be represented by a set of capacitated VRPs, one per each considered company. The MDVRP can be used to represent Scenarios 2 and 3. Finally, scenario 4 can be modeled as an integrated LRP.

The first approach to solve the problem is based on two main concepts. The initial idea is to develop a relatively easy-to-implement algorithm without too many parameters. In addition, we make use of Biased Randomization (BR) techniques (Juan et al., 2013) to obtain good-quality solutions, which are then integrated inside a traditional Iterated Local Search (ILS) framework (Lourenco et al., 2010). BR has been successfully used in several fields. Dominguez et al. (2014) apply a biased randomized constructive routing heuristic to solve the two-dimensional capacitated VRP. Alvarez Fernandez et al. (2018) used a BR-ILS to tackle a particular facility location problem: the uncapacitated single allocation $p$-hub median 
problem. Likewise, BR has been profitably applied to scheduling problem in Gonzalez-Neira et al. (2017). In order to better guide the random search process, BR techniques introduce biased (non-uniform) randomness in such a way that the logic behind the deterministic heuristic is conserved (Grasas et al., 2016). Thus, to generate random but good solutions a biased-randomized version of the classical CWS heuristic is used.

Two main phases define our solving strategy: (i) generation and selection of feasible and most promising solutions; and (ii) enhancement of the selected solutions. To generate feasible solutions the problem is divided into a set of successive steps and the complexity of the problem is lowered by using simple and fast procedures. Indeed, the first step in the construction of a new solution consists of deciding which depots to open. Because scenarios 1, 2, and 3 do not contemplate UCCs, all depots are opened. In the fourth scenario, all depots belonging to non-cooperative companies are opened (but they can also be used by the owner). Moreover, a random subset of the shared depots is also opened. The second step of the constructive phase consists of assigning the customers to the opened depots. Each client is served by a specific company. The clients of companies that are not cooperating are assigned to the depot of the company to which they are affiliated. The remaining customers are randomly assigned to some of the shared depots. In the last step, the routes are created with the biased-randomized version of the aforementioned CWS heuristic (BR-CWS). An example of the constructive phase is depicted in Fig. 1.
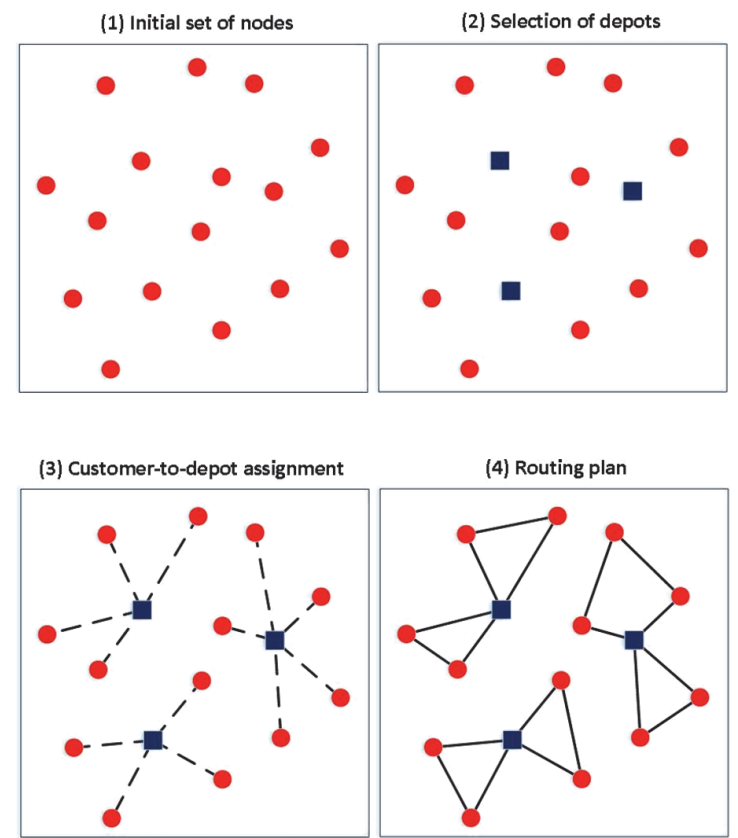

Fig. 1. Construction of a new solution.

The pseudo-code of the algorithm is depicted in Algorithm 1. Line 2 identifies the first phase of the algorithm. The second phase (lines 3-27) represent the ILS framework. Each of the best $n S o l$ solutions generated in the first phase are processed by the ILS in order to improve their quality. At each iteration, the base solution is perturbed in order to increase the diversification of the algorithm (line 6), and a local search is applied to the solution obtained (line 9). If the new solution is better than the base solution, the latter is updated (lines 11-13); otherwise a Demon-based acceptance criterion -based on the concept of accumulated credit- is used to accept even worst solutions (lines 16-18). At the end, the output of the algorithm is the best solution that it could find (line 27). The perturbation operation aims at modifying the customer-to-depot allocation. A percentage of shared customers are reassigned to the shared depots and the BR-CWS heuristic is used to generate the routes. The local search operator that was applied is a 2-opt intra-route exchange. 


\section{Computational Experiments}

The proposed solving framework was implemented as a Java application and tested on a Dell Workstation Precision Tower Serie 7000 (7910), with CPU Intel Xeon E5-2650 at 2.2GHz and 32GB of RAM. Each instance was solved using ten different random seeds. Thus, the reported results correspond to the bestfound solution in these runs. After a quick parameter fine-tuning experimentation, the following parameter settings are applied for our BR-ILS algorithm:

- Stopping criterion for the first phase: 1000 iterations.

- Probability distribution for the biased-randomized process in the constructive phase: geometric distribution with a parameter $\beta$, which is randomly selected in the interval $(0.07,0.23)$.

- Perturbation (customers re-allocation) percentage: a random value is selected in the interval $(0.1,0.5)$.

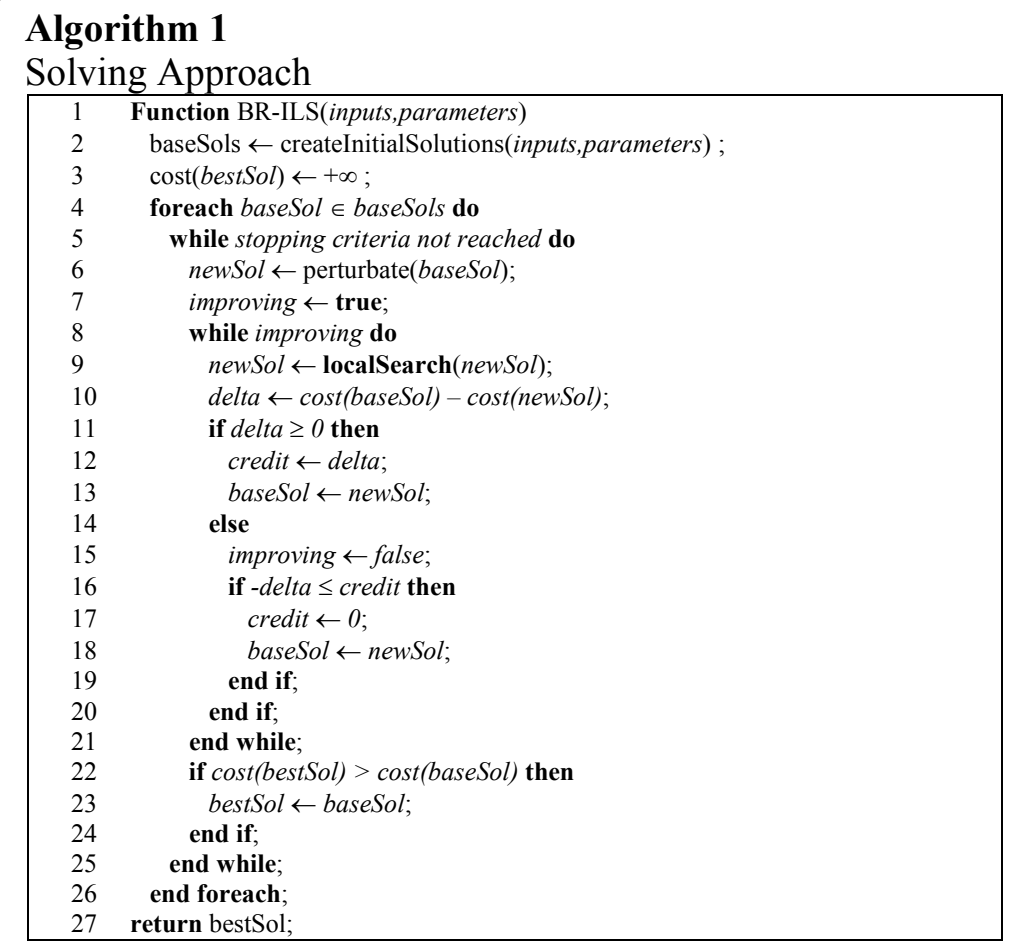

The proposed algorithm was used to solve the problem instances proposed by Akca et al. (2009), in order to validate its performance. Then, we compared our results to the corresponding best-known solutions (BKS) reported in literature. As shown in Table 1 our algorithm has an average gap of $0.36 \%$ with respect to the BKS. Moreover, we reach 3 BKS over 12 instances and our worst gap is below $1 \%$. Next, we adapted the instances from Akca et al. (2009) for each of the considered scenarios. The possible facility locations are capacitated, and the vehicles are homogeneous and capacitated. The objective is to minimize the overall distribution cost, which is computed as the sum of facility opening, vehicle, and routing costs. In order to represent the scenarios without UCCs, it is assumed that all possible facility locations are opened. Also, the $\mathrm{CO}_{2}$ emissions model employed in the study by Ubeda et al. (2011) is used here to estimate the environmental impact of the different scenarios. Since this model calculates CO2 emissions depending on traveled distance and vehicle load, travel distances and vehicle loads are estimated as outlined in Table 2. The emissions depend also on the direction of the delivery route. Since customers have different demands, the load of the vehicle in a given edge will be different depending on the direction of the route. Therefore, emissions for each route are calculated in both directions. The reported emissions represent the lowest value obtained for both computations. 
Table 1

Comparison of our results against BKS for the CLRP - Akca's set

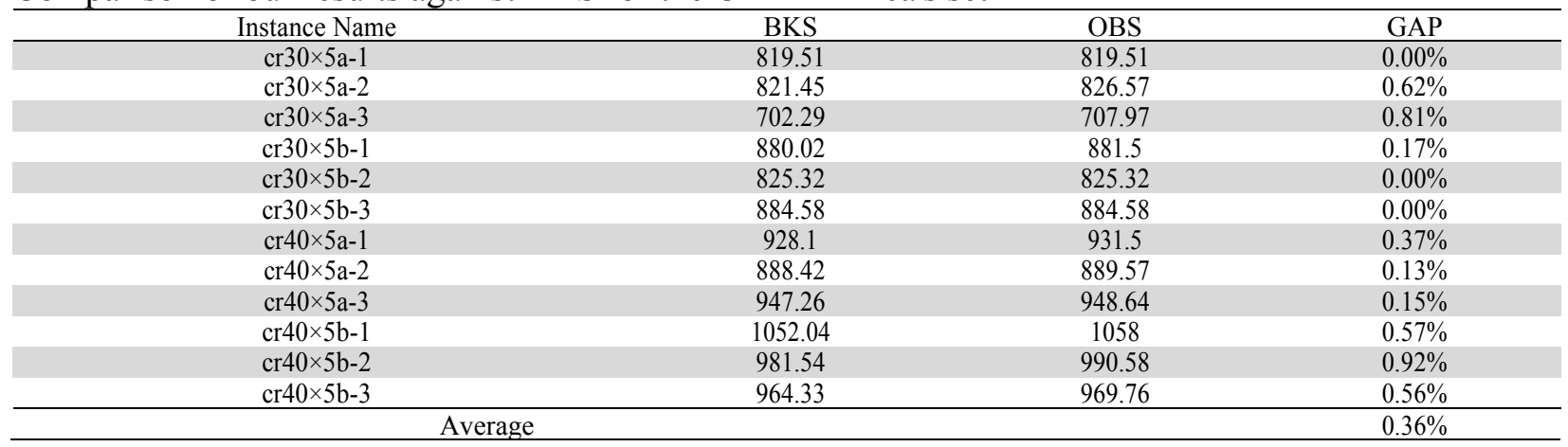

Table 2

Estimation of Emission Factors (Adapted from Ubeda et al. (2011))

\begin{tabular}{ccccc}
$\begin{array}{c}\text { Vehicle } \\
\text { load }\end{array}$ & $\begin{array}{c}\text { Load } \\
\text { Percentage }\end{array}$ & $\begin{array}{c}\text { Consumption } \\
(1 / 100 \mathrm{~km})\end{array}$ & $\begin{array}{c}\text { Conversion factor } \\
\left(\mathrm{kg} \mathrm{CO}_{2} / \mathrm{l}\right)\end{array}$ & $\begin{array}{c}\text { Emission factor } \\
(\mathrm{kg} \mathrm{CO} / \mathrm{km})\end{array}$ \\
\hline Empty & {$[0-25)$} & 29.6 & & 0.773 \\
Low & {$[25-50)$} & 32 & $\times 2.61$ & 0.831 \\
Half & {$[50-75)$} & 34.4 & & 0.900 \\
High & {$[0.75-100)$} & 36.7 & & 0.958 \\
Full & 100 & 39 & 1.018 \\
\hline
\end{tabular}

Table 3

Results for Scenarios 1 and 2

\begin{tabular}{|c|c|c|c|c|c|c|c|c|c|c|c|c|c|c|c|c|}
\hline \multirow[b]{2}{*}{ Instance } & \multicolumn{4}{|c|}{ Scenario 1} & \multicolumn{12}{|c|}{ Scenario 2} \\
\hline & $\begin{array}{c}\text { Opening } \\
\text { Cost }\end{array}$ & $\begin{array}{c}\text { Routing } \\
\text { Cost }\end{array}$ & $\begin{array}{l}\text { Total } \\
\text { Cost }\end{array}$ & $\mathrm{CO}_{2}$ & $\begin{array}{l}\text { Opening } \\
\text { Cost }\end{array}$ & $\begin{array}{c}50 \% \\
\text { Routing } \\
\text { Cost }\end{array}$ & $\begin{array}{l}\text { Total } \\
\text { Cost }\end{array}$ & $\mathrm{CO}_{2}$ & $\begin{array}{c}\text { Opening } \\
\text { Cost }\end{array}$ & $\begin{array}{c}75 \% \\
\text { Routing } \\
\text { Cost }\end{array}$ & $\begin{array}{l}\text { Total } \\
\text { Cost }\end{array}$ & $\mathrm{CO}_{2}$ & $\begin{array}{c}\text { Opening } \\
\text { Cost }\end{array}$ & $\begin{array}{c}100 \% \\
\text { Routing } \\
\text { Cost }\end{array}$ & $\begin{array}{l}\text { Total } \\
\text { Cost }\end{array}$ & $\mathrm{CO}_{2}$ \\
\hline $\operatorname{cr} 30 \times 5 a-1$ & 500 & 1401.39 & 1901.39 & 1179.93 & 500 & 1401.39 & 1901.39 & 1179.93 & 500 & 1390.80 & 1890.80 & 1170.59 & 500 & 1351.75 & 1851.75 & 1133.15 \\
\hline $\operatorname{cr} 30 \times 5 a-2$ & 500 & 1475.41 & 1975.41 & 1246.66 & 500 & 1415.65 & 1915.65 & 1183.38 & 500 & 1387.12 & 1887.12 & 1169.25 & 500 & 1366.39 & 1866.39 & 1144.88 \\
\hline $\operatorname{cr} 30 \times 5 a-3$ & 500 & 1109.65 & 1609.65 & 941.14 & 500 & 1109.65 & 1609.65 & 941.14 & 500 & 1094.64 & 1594.64 & 923.14 & 500 & 1094.64 & 1594.64 & 923.14 \\
\hline cr $30 \times 5 b-1$ & 500 & 1601.15 & 2101.15 & 1336.37 & 500 & 1539.40 & 2039.40 & 1271.04 & 500 & 1601.04 & 2101.04 & 1339.48 & 500 & 1443.94 & 1943.94 & 1206.94 \\
\hline $\operatorname{cr} 30 \times 5 b-2$ & 500 & 1537.81 & 2037.81 & 1316.19 & 500 & 1504.27 & 2004.27 & 1261.56 & 0 & 1491.72 & 1991.72 & 6.24 & 5 & 1485.46 & 5.46 & 1271.74 \\
\hline $\operatorname{cr} 30 \times 5 b-3$ & 500 & 1399.87 & 1899.87 & 1180.55 & 500 & 1364.58 & 1864.58 & 1149.44 & 500 & 1374.63 & 1874.63 & 1160.30 & 500 & 1359.74 & 1859.74 & 1147.66 \\
\hline $\operatorname{cr} 40 \times 5 a-1$ & 500 & 1388.28 & 1888.28 & 1170.23 & 500 & 1388.28 & 1888.28 & 1170.23 & 500 & 1339.59 & 1839.59 & 1125.00 & 500 & 1345.28 & 1845.28 & 1137.70 \\
\hline $\operatorname{cr} 40 \times 5 a-2$ & 500 & 1722.27 & 2222.27 & 1474.20 & 500 & 1689.83 & 2189.83 & 1374.71 & 500 & 1596.52 & 2096.52 & 1341.31 & 500 & 1629.35 & 2129.35 & 1355.49 \\
\hline $\operatorname{cr} 40 \times 5 a-3$ & 500 & 1458.21 & 1958.21 & 1229.49 & 500 & 1458.21 & 1958.21 & 1229.49 & 500 & 1424.10 & 1924.10 & 1204.26 & 500 & 1354.04 & 1854.04 & 1126.42 \\
\hline cr $40 \times 5 b-1$ & 500 & 1903.30 & 2403.30 & 1614.70 & 500 & 1784.49 & 2284.49 & 1485.61 & 500 & 1847.21 & 2347.21 & 1560.99 & 500 & 1683.55 & 2183.55 & 1408.41 \\
\hline $\operatorname{cr} 40 \times 5 b-2$ & 500 & 1815.70 & 2315.70 & 1529.76 & 500 & 1815.70 & 2315.70 & 1529.76 & 500 & 1690.02 & 2190.02 & 1422.33 & 500 & 1707.24 & 2207.24 & 1432.66 \\
\hline cr $40 \times 5 b-3$ & 500 & 1576.11 & 2076.11 & 1327.36 & 500 & 1576.11 & 2076.11 & 1327.36 & 500 & 1575.36 & 2075.36 & 1323.12 & 500 & 1549.84 & 2049.84 & 1310.07 \\
\hline Average & 500 & 1532.43 & 2032.43 & 1295.55 & 500 & 1503.96 & 2003.96 & 1258.64 & 500 & 1484.40 & 1984.40 & 1251.33 & 500 & 1447.60 & 1947.60 & 1216.52 \\
\hline
\end{tabular}

Table 4

Results for Scenario 3

\begin{tabular}{|c|c|c|c|c|c|c|c|c|c|c|c|c|}
\hline \multirow[b]{3}{*}{ Instance } & \multicolumn{12}{|c|}{ Scenario 3} \\
\hline & \multicolumn{4}{|c|}{$50 \%$} & \multicolumn{4}{|c|}{$75 \%$} & \multicolumn{4}{|c|}{$100 \%$} \\
\hline & $\begin{array}{c}\text { Opening } \\
\text { Cost }\end{array}$ & $\begin{array}{c}\text { Routing } \\
\text { Cost }\end{array}$ & $\begin{array}{l}\text { Total } \\
\text { Cost }\end{array}$ & $\mathrm{CO}_{2}$ & $\begin{array}{c}\text { Opening } \\
\text { Cost }\end{array}$ & $\begin{array}{c}\text { Routing } \\
\text { Cost }\end{array}$ & $\begin{array}{l}\text { Total } \\
\text { Cost }\end{array}$ & $\mathrm{CO}_{2}$ & $\begin{array}{c}\text { Opening } \\
\text { Cost }\end{array}$ & $\begin{array}{c}\text { Routing } \\
\text { Cost }\end{array}$ & $\begin{array}{l}\text { Total } \\
\text { Cost }\end{array}$ & $\mathrm{CO}_{2}$ \\
\hline $\mathrm{cr} 30 \times 5 \mathrm{a}-1$ & 500 & 1229.55 & 1729.55 & 1032.86 & 500 & 1069.97 & 1569.97 & 915.98 & 500 & 964.38 & 1464.38 & 817.34 \\
\hline $\operatorname{cr} 30 \times 5 a-2$ & 500 & 1258.38 & 1758.38 & 1062.01 & 500 & 1112.68 & 1612.68 & 942.97 & 500 & 928.86 & 1428.86 & 783.74 \\
\hline $\operatorname{cr} 30 \times 5 a-3$ & 500 & 993.73 & 1493.73 & 850.36 & 500 & 863.89 & 1363.89 & 737.81 & 500 & 725.08 & 1225.08 & 597.51 \\
\hline $\operatorname{cr} 30 \times 5 b-1$ & 500 & 1442.80 & 1942.80 & 1203.95 & 500 & 1141.09 & 1641.09 & 978.79 & 500 & 1055.46 & 1555.46 & 888.78 \\
\hline cr $30 \times 5 b-2$ & 500 & 1396.47 & 1896.47 & 1190.31 & 500 & 1274.17 & 1774.17 & 1085.34 & 500 & 1000.11 & 1500.11 & 844.41 \\
\hline cr $30 \times 5 b-3$ & 500 & 1302.21 & 1802.21 & 1098.84 & 500 & 1164.49 & 1664.49 & 990.12 & 500 & 1006.23 & 1506.23 & 860.86 \\
\hline $\operatorname{cr} 40 \times 5 a-1$ & 500 & 1248.31 & 1748.31 & 1040.92 & 500 & 1160.09 & 1660.09 & 977.40 & 500 & 990.48 & 1490.48 & 831.55 \\
\hline $\operatorname{cr} 40 \times 5 a-2$ & 500 & 1473.50 & 1973.50 & 1241.14 & 500 & 1396.45 & 1896.45 & 1182.44 & 500 & 1067.98 & 1567.98 & 906.37 \\
\hline $\operatorname{cr} 40 \times 5 a-3$ & 500 & 1330.54 & 1830.54 & 1126.42 & 500 & 1147.16 & 1647.16 & 973.18 & 500 & 1030.62 & 1530.62 & 874.14 \\
\hline $\operatorname{cr} 40 \times 5 b-1$ & 500 & 1675.46 & 2175.46 & 1425.90 & 500 & 1405.33 & 1905.33 & 1182.64 & 500 & 1237.57 & 1737.57 & 1062.63 \\
\hline cr $40 \times 5 b-2$ & 500 & 1551.41 & 2051.41 & 1308.57 & 500 & 1420.08 & 1920.08 & 1214.20 & 500 & 1156.36 & 1656.36 & 995.52 \\
\hline cr $40 \times 5 b-3$ & 500 & 1425.17 & 1925.17 & 1214.94 & 500 & 1307.25 & 1807.25 & 1106.41 & 500 & 1090.18 & 1590.18 & 933.07 \\
\hline Av & 500 & 1360.63 & 1860.63 & 1149.68 & 500 & 1205.22 & 1705.22 & 1023.94 & 500 & 21.11 & 1521.11 & 66.33 \\
\hline
\end{tabular}


Table 5

Results for Scenario 4

\begin{tabular}{|c|c|c|c|c|c|c|c|c|c|c|c|c|}
\hline \multirow[b]{3}{*}{ Instance } & \multicolumn{12}{|c|}{ Scenario 4} \\
\hline & & $50 \%$ & & & & $75 \%$ & & & & $100^{\circ}$ & & \\
\hline & $\begin{array}{c}\text { Opening } \\
\text { Cost }\end{array}$ & $\begin{array}{c}\text { Routing } \\
\text { Cost }\end{array}$ & $\begin{array}{l}\text { Total } \\
\text { Cost }\end{array}$ & $\mathrm{CO}_{2}$ & $\begin{array}{c}\text { Opening } \\
\text { Cost }\end{array}$ & $\begin{array}{c}\text { Routing } \\
\text { Cost }\end{array}$ & $\begin{array}{l}\text { Total } \\
\text { Cost }\end{array}$ & $\mathrm{CO}_{2}$ & $\begin{array}{c}\text { Opening } \\
\text { Cost }\end{array}$ & $\begin{array}{c}\text { Routing } \\
\text { Cost }\end{array}$ & $\begin{array}{l}\text { Total } \\
\text { Cost }\end{array}$ & $\mathrm{CO}_{2}$ \\
\hline cr30×5a-1 & 400 & 1229.55 & 1629.55 & 1032.86 & 400 & 1051.66 & 1451.66 & 901.33 & 200 & 753.01 & 953.01 & 647.57 \\
\hline $\operatorname{cr} 30 \times 5 a-2$ & 400 & 1258.38 & 1658.38 & 1062.01 & 400 & 1094.35 & 1494.35 & 936.70 & 200 & 794.92 & 994.92 & 686.04 \\
\hline $\operatorname{cr} 30 \times 5 a-3$ & 400 & 993.73 & 1393.73 & 850.36 & 300 & 881.51 & 1181.51 & 762.12 & 200 & 645.16 & 845.16 & 553.23 \\
\hline $\operatorname{cr} 30 \times 5 b-1$ & 400 & 1447.67 & 1847.67 & 1209.26 & 300 & 1167.30 & 1467.30 & 994.74 & 200 & 876.25 & 1076.25 & 747.85 \\
\hline $\operatorname{cr} 30 \times 5 b-2$ & 400 & 1396.47 & 1796.47 & 1190.31 & 300 & 1248.47 & 1548.47 & 1067.27 & 200 & 864.18 & 1064.18 & 755.20 \\
\hline $\operatorname{cr} 30 \times 5 b-3$ & 400 & 1294.12 & 1694.12 & 1102.12 & 300 & 1160.54 & 1460.54 & 997.24 & 200 & 873.31 & 1073.31 & 757.19 \\
\hline cr $40 \times 5 a-1$ & 400 & 1301.30 & 1701.30 & 1091.43 & 300 & 1162.48 & 1462.48 & 984.24 & 200 & 850.95 & 1050.95 & 729.74 \\
\hline $\operatorname{cr} 40 \times 5 a-2$ & 400 & 1521.75 & 1921.75 & 1289.07 & 300 & 1366.66 & 1666.66 & 1162.70 & 200 & 864.93 & 1064.93 & 741.92 \\
\hline cr $40 \times 5 a-3$ & 400 & 1330.43 & 1730.43 & 1126.75 & 300 & 1114.06 & 1414.06 & 947.85 & 200 & 920.79 & 1120.79 & 787.08 \\
\hline cr $40 \times 5 b-1$ & 400 & 1675.46 & 2075.46 & 1425.90 & 300 & 1354.90 & 1654.90 & 1157.06 & 200 & 1047.02 & 1247.02 & 907.75 \\
\hline cr $40 \times 5 b-2$ & 400 & 1577.87 & 1977.87 & 1339.96 & 300 & 1330.84 & 1630.84 & 1142.67 & 200 & 957.04 & 1157.04 & 836.27 \\
\hline cr $40 \times 5 b-3$ & 400 & 1426.13 & 1826.13 & 1216.98 & 300 & 1256.29 & 1556.29 & 1071.23 & 200 & 964.63 & 1164.63 & 847.66 \\
\hline Average & 400 & 1371.07 & 1771.07 & 1161.42 & 316.66 & 1182.42 & 1499.09 & 1010.43 & 200 & 867.68 & 1067.68 & 749.79 \\
\hline
\end{tabular}

\section{Analysis of Results \& Insights}

Savings in costs and in $\mathrm{CO}_{2}$ emissions were expected as $\mathrm{HC}$ strategies were considered. The results reported in Tables 3 to 5 on the different scenarios confirm this hypothesis. Regarding the noncooperative scenario, $\mathrm{HC}$ entails cost savings of $4.17 \%, 25.16 \%$, and $47.47 \%$ in the first three, respectively, scenarios with $100 \%$ of cooperation in the fourth scenario. Emissions have a similar behavior, the environmental impact can be reduced by $6.10 \%, 33.13 \%$, and $42.13 \%$, respectively.

In general, our results suggest that both total costs and environmental impact can be reduced via the use of HC practices. Moreover, as showed by the results depicted in Fig. 2 and Fig. 3, the savings are strongly dependent on the cooperation percentage. Clearly, a higher level of cooperation among the agents induces larger benefits for both total costs and $\mathrm{CO}_{2}$ emissions. Adopting this approach in a real-life scenario can substantially optimize the total cost of transportation and, at the same time, reduce the environmental cost for all supply chain partners. Some of the main advantages are: (i) a substantial reduction in warehousing and maintenance cost; (ii) an opportunity to increase the capacity and service levels offered to customers; (iii) a reduction in transit times, with faster delivery of goods; (iv) a complete utilization of the vehicle capacity, as the routing is planned for customers of different companies; $(v) \mathrm{CO}_{2}$ emissions are reduced and shared among the partners for the last mile delivery, thus the carbon footprint of individual players is reduced; (vi) strategically planning in locating the consolidation centers and associated capacities and routing helps to better understand the market and the customers' needs; this also provides a great benefit as companies can provide better services to existing customers and business is improved; (vii) there can be a considerable advantage in economies of scale as the cost reduces and the delivery time increases; (viii) adopting a fully cooperative scenario provides benefits such as a reduction in individual investment costs, thorough research of the market, and higher levels of marketing and servicing.

\section{Conclusions}

This paper analyzes the use of $\mathrm{HC}$ concepts in routing and locations decisions. Four different scenarios are considered: (i) a non-cooperative scenario, in which all companies take decisions without any form of cooperation; (ii) a partial-cooperation scenario, in which the capacities of the depots are shared by different companies but each company uses its own fleet of vehicles to serve its clients; (iii) an advancedcooperation scenario, in which both depot capacities and vehicle fleets are shared; and (iv) a total cooperation scenario, in which also the decision about which depots have to be opened is shared. Moreover, each scenario (except the non-cooperative one) is investigated under different cooperation 
settings. Particularly, three percentage levels of cooperation among companies are taken in account for each scenario: $50 \%, 75 \%$, and $100 \%$.

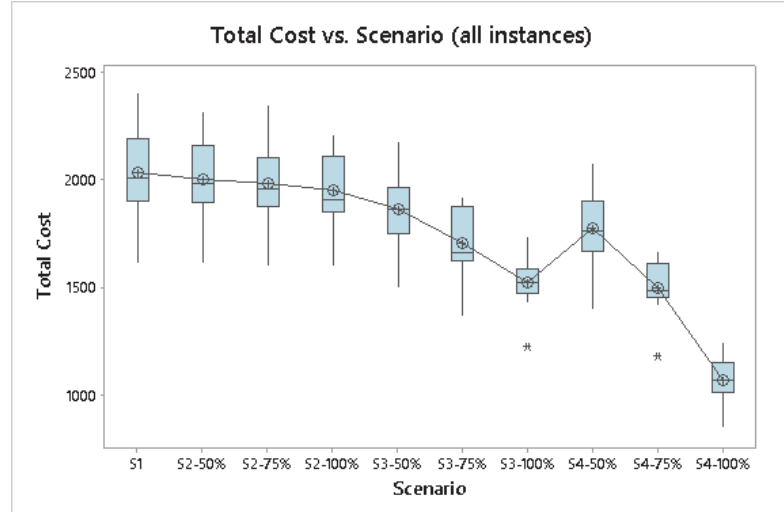

Fig. 2. Comparison of Total Costs for the Different Scenarios

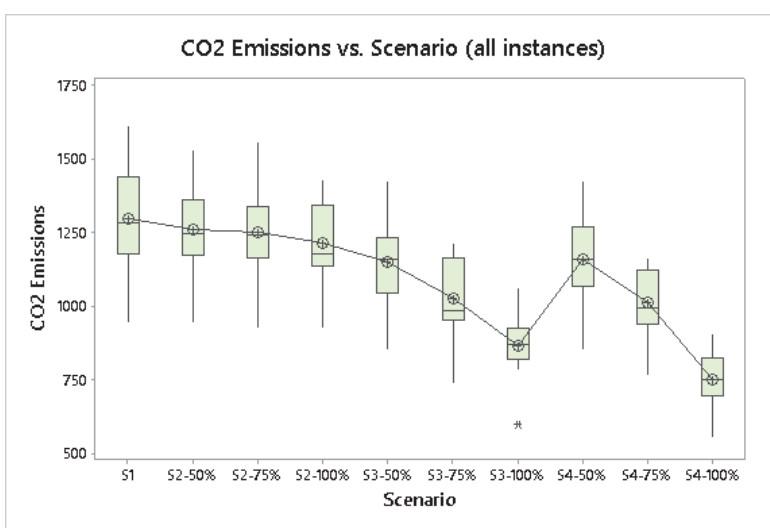

Fig. 3. Comparison of Total Cost for the Considered Scenarios

The different problem settings are solved with a metaheuristic algorithm, which combines BR and ILS. All scenarios are compared through extensive experiments employing a well-known benchmark set. Reported results suggest that significant overall costs savings and a reduction in $\mathrm{CO}_{2}$ emissions can be achieved with a higher degree of cooperation. Several research lines arise from this work. Some problem extensions introduce heterogeneous vehicles or the inclusion of stochastic values (demands, travel times, etc.) in order to tackle even more realistic scenarios.

\section{References}

Akca, Z., Berger, R., Ralphs, T., (2009). A branch-and-price algorithm for combined location and routing problems under capacity restrictions. In: Operations research and cyber-infrastructure. Springer, pp. 309-330.

Allen, J., Browne, M., Woodburn, A., \& Leonardi, J. (2012). The role of urban consolidation centres in sustainable freight transport. Transport Reviews, 32(4), 473-490.

Alvarez Fernandez, S., Ferone, D., Juan, A. A., Silva, D. G., \& de Armas, J., (2018). A 2-stage biasedrandomized iterated local search for the uncapacitated single allocation p-hub median problem. Transactions on Emerging Telecommunications Technologies, e3418.

Browne, M., Allen, J., \& Leonardi, J. (2011). Evaluating the use of an urban consolidation centre and electric vehicles in central London. IATSS Research, 35(1), 1-6.

Browne, M., Allen, J., Nemoto, T., Patier, D., \& Visser, J. (2012). Reducing social and environmental impacts of urban freight transport: a review of some major cities. Procedia-Social and Behavioral Sciences, 39, 19-33.

Clarke, G., \& Wright, J. W. (1964). Scheduling of vehicles from a central depot to a number of delivery points. Operations Research, 12(4), 568-581.

Cruijssen, F., Cools, M., \& Dullaert, W. (2007a). Horizontal cooperation in logistics: opportunities and impediments. Transportation Research Part E: Logistics and Transportation Review, 43(2), 129-142.

Cruijssen, F., Dullaert, W., \& Fleuren, H. (2007b). Horizontal cooperation in transport and logistics: a literature review. Transportation Journal, 46(3), 22-39.

De Assis Correia, V., de Oliveira, L. K., \& Guerra, A. L. (2012). Economical and environmental analysis of an urban consolidation center for Belo Horizonte city (brazil). Procedia-Social and Behavioral Sciences, 39, 770-782. 
Dominguez, O., Juan, A., \& Faulin, J. (2014). A biased-randomized algorithm for the two-dimensional vehicle routing problem with and without item rotations. International Transactions in Operational Research, 21(3), 375-398.

Gansterer, M., \& Hartl, R. F. (2018). Collaborative vehicle routing: a survey. European Journal of Operational Research, 268(1), 1-12.

Gogas, M. A., \& Nathanail, E. (2017). Evaluation of urban consolidation centers: a methodological framework. Procedia Engineering 178, 461-471.

Gonzalez-Neira, E. M., Ferone, D., Hatami, S., \& Juan, A. A., (2017). A biased-randomized simheuristic for the distributed assembly permutation flowshop problem with stochastic processing times. Simulation Modelling Practice and Theory, 79(Supplement C), 23 - 36.

Grasas, A., Juan, A. A., \& Lourenco, H. R. (2016). Simils: a simulation-based extension of the iterated local search metaheuristic for stochastic combinatorial optimization. Journal of Simulation, 10(1), 6977.

Grimm, N. B., Faeth, S. H., Golubiewski, N. E., Redman, C. L., Wu, J., Bai, X., \& Briggs, J. M. (2008). Global change and the ecology of cities, Science, 319(5864), 756-760.

Juan, A. A., Faulin, J., Ferrer, A., Lourenco, H. R., \& Barrios, B. (2013). MIRHA: multi-start biased randomization of heuristics with adaptive local search for solving non-smooth routing problems. TOP 21(1), 109-132.

Juan, A. A., Goentzel, J., \& Bektas, T. (2014). Routing fleets with multiple driving ranges: is it possible to use greener fleet configurations? Applied Soft Computing, 21, 84-94.

Lourenco, H. R., Martin, O. C., Stutzle, T., (2010). Iterated local search: Framework and applications. In: Handbook of metaheuristics. Springer, pp. 363-397.

Muñoz-Villamizar, A., Montoya-Torres, J. R., Juan, A. A., \& Caceres-Cruz, J. (2013). A simulationbased algorithm for the integrated location and routing problem in urban logistics. In: 2013 Winter Simulations Conference (WSC). pp. 2032-2041.

Muñoz-Villamizar, A., Quintero-Araújo, C. L., Montoya-Torres, J. R., \& Faulin, J. (2018). Short-and mid-term evaluation of the use of electric vehicles in urban freight transport collaborative networks: a case study. International Journal of Logistics Research and Applications, 1-24. https://doi.org/10.1080/13675567.2018.1513467

Nagy, G., \& Salhi, S. (2007). Location-routing: issues, models and methods. European Journal of Operational Research, 177(2), 649 - 672.

Patier, D., \& Browne, M. (2010). A methodology for the evaluation of urban logistics innovations. Procedia-Social and Behavioral Sciences, 2(3), 6229-6241.

Perez-Bernabeu, E., Juan, A. A., Faulin, J., \& Barrios, B. B. (2015). Horizontal cooperation in road transportation: a case illustrating savings in distances and greenhouse gas emissions. International Transactions in Operational Research, 22(3), 585-606.

Pomponi, F., Fratocchi, L., Tafuri, S. R., \& Palumbo, M. (2013). Horizontal collaboration in logistics: a comprehensive framework. Research in Logistics \& Production, 3.

Prins, C., Prodhon, C., \& Calvo, R. W. (2006). Solving the capacitated location-routing problem by a grasp complemented by a learning process and a path relinking. 4OR: A Quarterly Journal of Operations Research, 4(3), 221-238.

Prodhon, C., \& Prins, C. (2014). A survey of recent research on location-routing problems. European Journal of Operational Research, 238(1), 1-17.

Quintero-Araujo, C. L., Caballero-Villalobos, J. P., Juan, A. A., \& Montoya-Torres, J. R. (2017a). A biased-randomized metaheuristic for the capacitated location routing problem. International Transactions in Operational Research, 24(5), 1079-1098.

Quintero-Araujo, C. L., Gruler, A., Juan, A. A., de Armas, J., \& Ramalhinho, H. (2017b). Using simheuristics to promote horizontal collaboration in stochastic city logistics. Progress in Artificial Intelligence, 6(4), 275-284.

Quintero-Araujo, C. L., Gruler, A., Juan, A. A., \& Faulin, J. (2019). Using horizontal cooperation concepts in integrated routing and facility-location decisions. International Transactions in Operational Research, 26(2), 551-576. 
Quintero-Araujo, C. L., Juan, A. A., Montoya-Torres, J. R., Muñoz Villamizar, A., (2016). A simheuristic algorithm for horizontal cooperation in urban distribution: Application to a case study in colombia. In: Proceedings of the 2016 Winter Simulation Conference. IEEE Press, Piscataway, NJ, USA, pp. 2193-2204.

Reyes-Rubiano, L., Calvet, L., Juan, A. A., Faulin, J., \& Bove, L. (2018). A biased-randomized variable neighborhood search for sustainable multi-depot vehicle routing problems. Journal of Heuristics, 122.

Salhi, S., \& Rand, G. K. (1989). The effect of ignoring routes when locating depots. European Journal of Operational Research, 39(2), 150 - 156.

Serrano-Hernández, A., Juan, A. A., Faulin, J., \& Perez-Bernabeu, E. (2017). Horizontal collaboration in freight transport: concepts, benefits and environmental challenges. SORT-Statistics and Operations Research Transactions, 1(2), 393-414.

Thompson, R. G., \& Taniguchi, E., (2008). City logistics and freight transport. In: Handbook of logistics and supply-chain management. Emerald Group Publishing Limited, pp. 393-405.

Ubeda, S., Arcelus, F., Faulin, J., (2011). Green logistics at Eroski: a case study. International Journal of Production Economics, 131(1), 44 - 51.

Van Binsbergen, A., \& Visser, J. (1999). New urban goods distribution systems. In: Conference on Urban Transport Systems.

Van Rooijen, T., \& Quak, H. (2010). Local impacts of a new urban consolidation centre the case of Binnenstad service. Procedia-Social and Behavioral Sciences, 2(3), 5967-5979.

Vanovermeire, C., Srensen, K., Breedam, A. V., Vannieuwenhuyse, B., \& Verstrepen, S. (2014). Horizontal logistics collaboration: decreasing costs through exibility and an adequate cost allocation strategy. International Journal of Logistics Re-search and Applications, 17(4), 339-355.

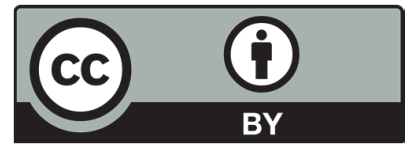

(C) 2019 by the authors; licensee Growing Science, Canada. This is an open access article distributed under the terms and conditions of the Creative Commons Attribution (CCBY) license (http://creativecommons.org/licenses/by/4.0/). 